\title{
Pharmacoligical characterization of the iranian Cerastes cerastes gasperettii (Reptilia: Ophidia: Viperidae) venom
}

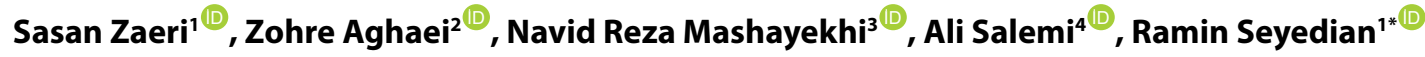 \\ 'Department of Pharmacology, Bushehr University of Medical Sciences, Bushehr, Iran \\ 2Department of Physiology, School of Medicine, Shiraz University of Medical Sciences, Shiraz, Iran \\ 'Department of Internal Medicine, Cardiology Division, Arak University of Medical Sciences, Arak, Iran \\ ${ }^{4}$ Department of Human Vaccine and Serum, Razi Vaccine and Serum Research Institute, Agricultural Research, Education and \\ Extension Organization, Karaj, Iran
}

\author{
Received: 27 April 2021 \\ Accepted: 8 June 2021 \\ Published online: 17 June 2021 \\ *Corresponding author: \\ Ramin Seyedian, \\ Department of Pharmacology, \\ Bushehr University of Medical \\ Sciences, Bushehr, Iran, \\ Email: raminseyedian@gmail.com \\ Competing interests: None \\ declared. \\ Funding information: None. \\ Citation: Zaeri S, Aghaei Z \\ Mashayekhi NR, Salemi A, Seyedian \\ R. Pharmacoligical characterization \\ of the iranian Cerastes cerastes \\ gasperettii (Reptilia: Ophidia: \\ Viperidae) venom. Journal of \\ Emergency Practice and Trauma \\ 2021; 7(2): 123-126. doi: 10.34172/ \\ jept.2021.22
}

\begin{abstract}
Objective: Snake envenomation is common in tropical and subtropical countries of the Middle East areas including Iran. Cerastes cerastes gasperettii is a dangerous snake living in southwestern provinces of Iran. It causes massive edema at the bite site and coagulopathy leading to death if untreated.

Methods: The purpose of this preliminary animal study was to evaluate the toxicity and proteomic of this venom for the first time in Iran. Moreover, the hemodynamic changes with intravenous injection of the venom were assessed and inotropic in addition to arrhythmogenic properties of this venom were investigated.

Results: The estimated amount of the LD50 with intraperitoneal injection was slightly less than the similar experiment in Saudi Arabia ( $1.32 \mathrm{mg} / \mathrm{kg}$ versus $978 \mu \mathrm{g} / \mathrm{kg}$ body weight) There were 8 distinct protein bands between 12 and $66 \mathrm{kDa}$ in SDS-PAGE analysis that were different with Moroccan experiment due to inter and intra species variation. Inotropic potencies were not significant since the lethal dose with intravenous injection was much lower than the Arabian experiment in guinea pigs ( $2.4 \mathrm{mg} / \mathrm{kg}$ versus $0.8 \mathrm{mg} / \mathrm{kg}$ ).

Conclusion: According to the low hemodynamic changes induced with the venom, it seems that coagulopathy and edema are the most dangerous effects of this rare snake in Iran.

Keywords: Snake, Hemodynamic, Proteomic, Cerastes gasperettii
\end{abstract}

\section{Introduction}

It is estimated that among 3000 known species of snakes all over the world, 27 are venomous and 11 are semivenomous spreading in $\operatorname{Iran}(1,2)$. Cerastes cerastes gasperettii (C.cg), known as horned viper, belongs to the Viperidae family and is one of the most dangerous snakes of the sandy deserts like southwestern areas especially Khuzestan province (3). This snake is the most common species in the Saudi Arabia and lives in Jordan, Egypt and Iraq as well $(4,5)$. There are some reports of life-threatening envenomation of this nocturnal snake including microangiopathic hemolytic edema and renal failure, while there is little knowledge about the toxicological aspects of its venom in Iran $(6,7)$.

Clinically, hemorrhagic wounds at the bite site are the common manifestations accompanied with coagulopathy, which probably stem from the snake venom metalloproteinases like Cerastes cerastes matrix metalloproteinase II (CCMP-II) $(8,9)$.

It is noted that cardiac complications are not considered primarily in all snake envenomation, but they usually provoke detrimental effects in human being (10).

Few studies have addressed the cardiovascular problems induced with C.c.gasperetti in experimental animals to clarify the hemodynamic manifestations of envenomation with this snake $(11,12)$. Although the conducted studies seem interesting, they failed to take into account the clinical implications probably due to the limited envenomation with this snake in Iran. This study aimed at evaluating the physiological changes in the inotropic, chronotropic and arrhythmogenic parameters in anesthetized rats with Iranian C.cg venom and to find its lethal potency (LD50) with intraperitoneal injections in mice. Additionally, the protein profile of the venom was extracted with SDSPAGE analysis. 


\section{Methods}

In this interventional animal study, the crude venom was prepared by milking of the C.cg snakes captured in Khuzestan province in the southwestern part of Iran (Figure 1).

The crude venom was lyophilized and stored at $-20^{\circ} \mathrm{C}$ until use. During each experiment, the venom was dissolved in normal saline solution and maintained at $4^{\circ} \mathrm{C}$. Mice and rats were acclimatized for 10 days in well ventilated free cages at room temperature $\left(20-30^{\circ} \mathrm{C}\right)$ in the animal house of the Bushehr University of Medical Science before the initiation of the study. All experiments were performed according to the Helsinki protocol.

To determine the lethality of the C.cg venom, it was intraperitoneally injected with different concentrations dissolved in normal saline to six groups ( $n=5$ in each) of 20-25 g male Swiss albino mice. The median lethal dose (LD50) was estimated 24 hours later by the probit analysis $(13,14)$.

The protein content was determined based on the Bradford method, using bovine serum albumin as standard (15).

The protein ingredients of the C.cg venom (5 and 10 $\mu \mathrm{g})$ in the non-reducing condition were resolved and electrophoresed at $90 \mathrm{~V}$ using $12.5 \%$ acrylamide gel as previously described (16). The protein bands were revealed after electrophoresis by staining with Coomassie Blue G-250 solution (Bio-Rad Laboratories) and were destained with distilled water. The protein ladder (CSL$\mathrm{BBL}$, Cleaver Company) was electrophoresed in the gel to determine the molecular weights of the ingredients (11$245 \mathrm{kDa})$.

Male Wistar rats weighting $250 \mathrm{~g}$-300 g were anesthetized with ketamine (100 mg/kg; i.p) and xylazine (10 mg/ $\mathrm{kg}$; i.p). They were also placed in supine position on the operating table. A left femoral incision was made and cannulas were inserted into the femoral vein and femoral artery for administration of venom and measurement of blood pressure, respectively. Hemodynamic changes (inotropic, chronotropic and arrhythmogenicity) were obtained with a PowerLab acquisition system (AD instrument, Australia). All animals were killed at the end of the study with cervical dislocation. Animals were administered (five in each group) intravenously with Cearstes cerastes gasperettii venoms (300, 1200 and 2400 $\mu \mathrm{g} / \mathrm{kg}$ ) dissolved in normal saline in two minutes. Control rats were injected with the same volume of the normal saline. Cardiovascular effects (e.g., bradycardia, hypo and /- or hypertension and arrhythmogenicity) were determined during the study.

Statistical analysis was performed by using IBM SPSS software version 19. Responses were expressed as mean \pm SD. Multiple comparisons were made using a one-way ANOVA followed by Tukey's test. A $P$ value $<0.01$ was considered as statistically significant.
Results

The results showed that the estimated amount of the LD50 of the venom with intraperitoneal injection was $1.32 \mathrm{mg} /$ $\mathrm{kg}$ body weight in mice.

Proteomic analysis of the C.cg venom revealed the presence of the components of at least 8 distinct bands between 12 and $66 \mathrm{kDa}$. There were 7 bands located at 12, $16,19,24,32,37$ and $66 \mathrm{kDa}$ and one fair band at $56 \mathrm{kDa}$ (Figure 2).

Contrary to the lower doses of the Cerastes cerastes gasperettii venom $(300,1200 \mu \mathrm{g} / \mathrm{kg})$, the higher dose $(2400 \mu \mathrm{g} / \mathrm{rat})$ caused a marked hypotensive effect in anesthetized animals leading to death in 8 minutes after injection (Figure 3).

\section{Discussion}

Cesrastes cerastes gasperettii is one of the most abundant snakes of the Middle Eastern areas and it is found in Khuzestan province in Iran. Hemorrhagic wound at the bite site and coagulopathy are the common clinical manifestations in the Saudi Arabia. Due to the rare reports of the snakebites in Iran, it is not possible to firmly express the envenomation effects and the best way of its management $(8,17)$.

Based on the results, the approximate lethality (LD50)

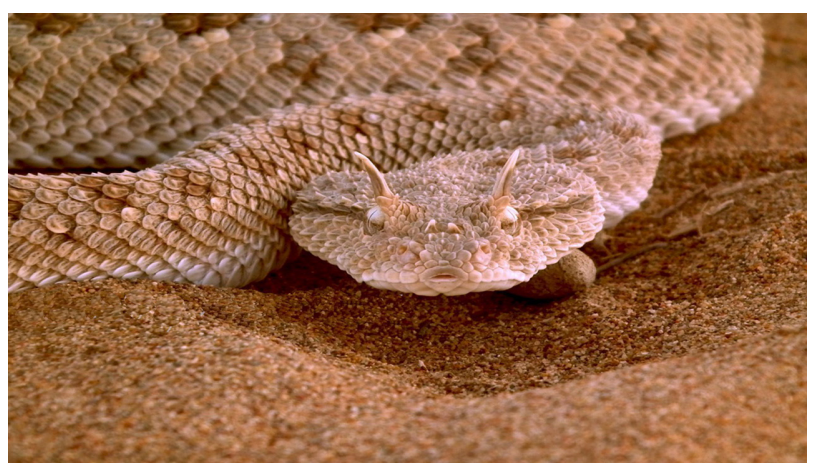

Figure 1. Cerastes cerastes gasperettii captured in the southwestern province of Iran.

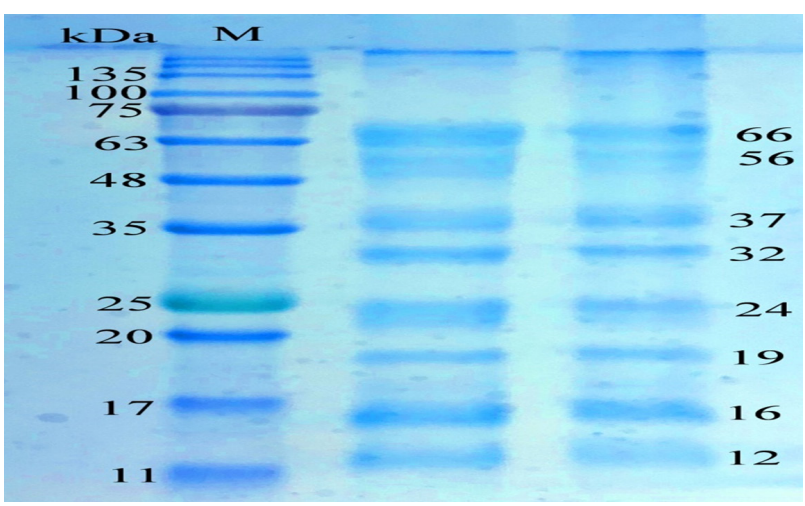

Figure 2. The protein constituents of the Cerastes cerastes gasperettii venom (lane 1:10 and lane 2:5 $\mu \mathrm{g}$ ) were separated with the SDS-PAGE stained with the Coomassie blue. Numbers show the molecular weights of the components. 


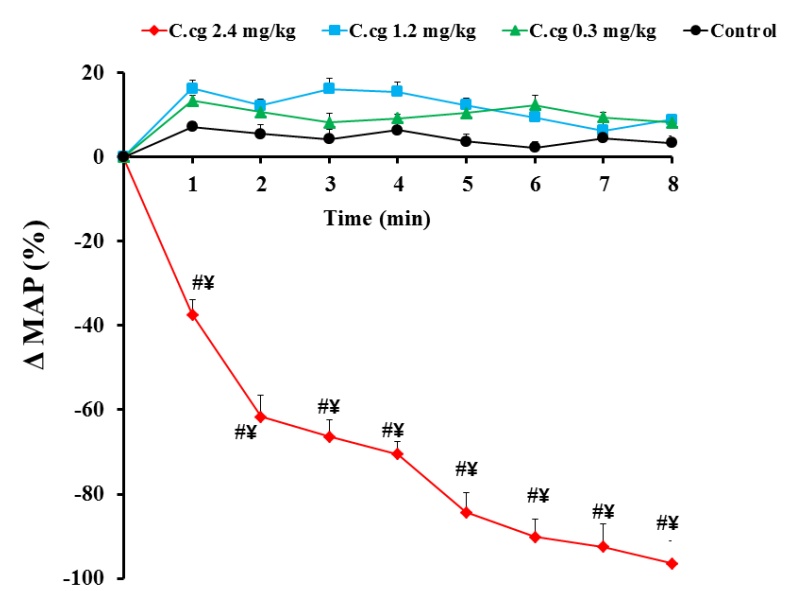

Figure 3. Changes in mean arterial pressure after intravenous administration of Cerastes cerastes gasperettii venom (300, 1200 and $2400 \mu \mathrm{g} / \mathrm{kg})$. Control rats $(n=5)$ received normal saline $(400 \mu \mathrm{L}$, i.v). The points represent the mean \pm SEM. $\#, *<0.01$ compared to the elementary value (time zero) of the same group and (\#) to the control group ( $¥)$.

of the Iranian snake was less than the previous reports performed in the Saudi Arabia (1.32 mg kg versus $978 \mu \mathrm{g} /$ $\mathrm{kg}$ body weight) probably due to the species variation (18).

The protein profile showed two bands around 32 $\mathrm{kDa}$ and $38 \mathrm{kDa}$ similar to the previous reports likely due to the snake matrix metalloproteinases $(9,19,20)$. Furthermore, it had 7 various extra bands different from the other experiment performed on the Moroccan snake. In our further examination, venom separation must be carried out with the sephadex column and HPLC to extract the molecular weight of the different enzymes such as hemorrhagic, fibrinogenolytic, and proteolytic.

As shown in Figure 3, our results demonstrate that the venom is weak to induce hemodynamic effects in rats compared to the previous experiment in guinea pigs $(2.4 \mathrm{mg} / \mathrm{kg}$ versus $0.8 \mathrm{mg} / \mathrm{kg}$ ). This can be due to inter or intraspecies variation (12). There was bradycardia in the lethal dose as observed also in the Arabian study but no arrhythmia was recorded before death in rats. It seems that cardiovascular injuries have little role in envenomed patients.

\section{Conclusion}

According to our results, it is evident that cardiovascular changes have a minor role in the envenomed patients compared to other snakes. This preliminary experiment paves the way for further examination to separate different metalloenzymes causing pathological manifestations in stung patients.

\section{Authors' contribution}

This study was designed and performed by RS and SZ. Venom extraction and toxicological experiments were performed by AS and ZA, while the hemodynamic interpretation was analyzed by NRM. All authors accepted the final revision.

\section{Ethical Issues}

This animal study was conducted by the local research ethics committee of the Bushehr University with code number IR.BPUMS.REC.1398.133.

\section{Acknowledgements}

The authors express their gratitude to B Bushehr University of Medical Sciences Research Center for providing facilities.

\section{References}

1. Dehghani R, Fathi B, Shahi MP, Jazayeri M. Ten years of snakebites in Iran. Toxicon 2014; 90: 291-8. doi: 10.1016/j. toxicon.2014.08.063.

2. Latifi M. Variation in yield and lethality of venoms from Iranian snakes. Toxicon 1984; 22(3): 373-80. doi: 10.1016/0041-0101(84)90081-3.

3. Stümpel N, Joger U. Recent advances in phylogeny and taxonomy of Near and Middle Eastern Vipers-an update. ZooKeys 2009; 31: 179-91. doi: 10.3897/zookeys.31.261.

4. Al-Sadoon MK, Paray BA. Ecological aspects of the horned viper, Cerastes cerastes gasperettii in the central region of Saudi Arabia. Saudi J Biol Sci 2016; 23(1): 135-8. doi: 10.1016/j.sjbs.2015.10.010.

5. Rhadi FA, Rastegar-Pouyani N, Mohammed RG, Karamiani R. On the occurrence and range extension of the nominotypic form of the Arabian horned viper, Cerastes g. gasperettii, Leviton and Anderson 1967, (Ophidia: Viperidae), in central and southern Iraq. Amphib Reptile Conserv 2015; 9(2): 1-5.

6. Schneemann M, Cathomas R, Laidlaw ST, El Nahas AM, Theakston RD, Warrell DA. Life-threatening envenoming by the Saharan horned viper (Cerastes cerastes) causing micro-angiopathic haemolysis, coagulopathy and acute renal failure: clinical cases and review. QJM 2004; 97(11): 717-27. doi: 10.1093/qjmed/hch118.

7. Salman MM. Effects of different doses of Cerastes cerastes crude venom on biochemical parameters in serum of guinea pigs at different times. Biol Forum 2014; 6(2): 329-39.

8. Lifshitz M, Kastel H, Harman-Boehm I. Cerastes cerastes envenomation in an 18 year old female: a case report. Toxicon 2002; 40(8): 1227-229. doi: 10.1016/s00410101(02)00124-1.

9. Boukhalfa-Abib H, Laraba-Djebari F. CcMP-II, a new hemorrhagic metalloproteinase from Cerastes cerastes snake venom: purification, biochemical characterization and amino acid sequence analysis. Comp Biochem Physiol C Toxicol Pharmacol 2015; 167: 65-73. doi: 10.1016/j. cbpc.2014.09.004.

10. Virmani SK. Cardiac involvement in snake bite. Med J Armed Forces India 2002; 58(2): 156-7. doi: 10.1016/s03771237(02)80054-5.

11. Mohamed H, Khaled LZ. Effect of Cerastes cerastes venom on blood and tissue histamine and on arterial blood pressure. Toxicon 1969; 6(3): 221-3. doi: 10.1016/00410101(69)90122-6.

12. Abdalla S, Bilto Y, Disi A. Effects of sand viper (Cerastes cerastes) venom on isolated smooth muscle and heart 
and on haematological and cardiovascular parameters in the guinea-pig. Toxicon 1992; 30(10): 1247-55. doi: 10.1016/0041-0101(92)90441-7.

13. Ashford JR, Sowden RR. Multi-variate probit analysis. Biometrics 1970; 26(3): 535-46.

14. Theakston RD, Reid HA. Development of simple standard assay procedures for the characterization of snake venom. Bull World Health Organ 1983; 61(6): 949-56.

15. Bradford MM. A rapid and sensitive method for the quantitation of microgram quantities of protein utilizing the principle of protein-dye binding. Anal Biochem 1976; 72(1-2): 248-54. doi: 10.1006/abio.1976.9999.

16. Laemmli UK. Cleavage of structural proteins during the assembly of the head of bacteriophage T4. Nature 1970; 227(5259): 680-5. doi: 10.1038/227680a0.

17. Al-Sadoon MK, Diab M, Bauomy AA, Moneim AE. Cerastes cerastes gasperettii venom induced hematological alterations and oxidative stress in male mice. J Pure Appl Microbiol 2014; 8(Suppl 2): 693-702. doi: 10.1002/cbf.2858

18. Al-Sadoon MK, Abdel Moneim AE, Bauomy AA, Diab M. Histochemical and biochemical effects induced by LD50 of Cerastes cerastes gasperetti crude venom in mice. Life Sci J 2013; 10(4): 810-7.

19. Oukkache N, Lalaoui M, Ghalim N. General characterization of venom from the Moroccan snakes Macrovipera mauritanica and Cerastes cerastes. J Venom Anim Toxins Incl Trop Dis 2012; 18(4): 411-20. doi: 10.1590/s1678-91992012000400009.

20. Tachoua W, Boukhalfa-Abib H, Laraba-Djebari F. Hemorrhagic metalloproteinase, Cc HSM-III, isolated from Cerastes cerastes venom: purification and biochemical characterization. J Biochem Mol Toxicol 2017; 31(7). doi: 10.1002/jbt.21899. 